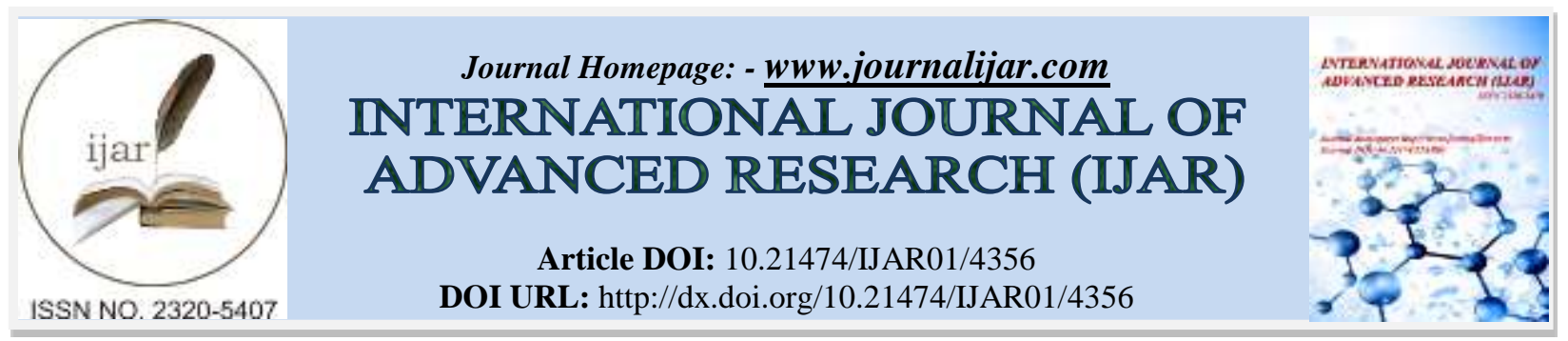

RESEARCH ARTICLE

\title{
A COMPARATIVE, HOSPITAL BASED PROSPECTIVE STUDY OF FLUSH LIGATION OF SAPHENOFEMORAL JUNCTION WITH AND WITHOUT STRIPPING OF LONG SAPHENOUS VEIN AS A MODALITY OF TREATMENT FOR LONG SAPHENOUS VARICOSE VEINS.
}

\section{Zaffar Ahmad Anim ${ }^{1}$, Adil Pervaiz Shah ${ }^{1}$, Perveez Ahmad Malik ${ }^{1 *}$, Shaheena Anim², Seth Mujtaba Hussain ${ }^{1}$ and Tariq hassan dug ${ }^{1}$.}

1. Department of general \& minimal access surgery, SKIMS Medical College, Bemina Srinagar.

2. Department of gynaecology \& obstetrics, Government Medical College \& Associated Hospital, Srinagar.

\section{Manuscript Info}

\section{Manuscript History}

Received: 23 March 2017

Final Accepted: 25 April 2017

Published: May 2017

Key words:-

Varicose veins, Saphenofemoral,

Trendelenburg's surgery, stripping

\section{Abstract}

Purpose: Varicose veins are dilated, tortuous, thin elongated vessels usually associated with valvular incompetence. With a shift to less invasive, endovenous treatment modalities in recent years, much attention and interest has been drawn to venous disease. In this study, our focus was to compare between the two surgical techniques as standard procedure when less invasive and more recent technique modalities as treatment are not yet available.

Methods: The study comprised of 100 cases of long saphenous varicosities. Each patient was subjected to Doppler ultrasound to look for saphenofemoral incompetence and patency of deep veins. The patients were allocated into two groups of 50 patients each who either went flush ligation of saphenofemoral junction with stripping of long saphenous varicose vein or Trendelenburg's surgery (flush ligation of saphenofemoral junction), and were called by $\mathbf{S}$ and $\mathbf{T}$ group respectively.

Results: We observed that saphenofemoral ligation with or without stripping is equally effective in long saphenonous varicosities. However, saphenofemoral ligation with stripping which aims to remove the varicose vein produces lasting results and overall better outcome.

Conclusion: The study concludes that long saphenous varicosities are best treated by stripping in spite of the fact that the period of disability following surgery is significantly longer that after Saphenofemoral Junction Ligation only.

Copy Right, IJAR, 2016,. All rights reserved.

\section{Introduction: -}

Varicose veins have plagued the human beings throughout the history, perhaps this degenerative condition, in which the valves of the superficial veins become incompetent, is apparently the result of man's assuming an upright position, walking on two legs rather than four. The delicate valves that evolved through millions of years of ambulation on four legs are unable to withstand the increased gravitational pressure of our newly acquired upright posture. Varicose veins are among the most easily recognized vascular abnormalities, with superficial venous tortuosity and enlargement. It is a common condition affecting more than 25 million people in the United States alone (1), with a complex and multi-factorial development involving interplay between the genetic makeup of the

Corresponding Author:- Dr perveez ahmad malik.

Address:- Department of general \& minimal access surgery, SKIMS Medical College, Bemina Srinagar. 
individual and predisposing risk factors that include age, female sex, family history, pregnancy, obesity, and prolonged standing (2). The genetic basis of varicose veins remains to be elucidated; it is clear they can arise in young individuals with no predisposing risk factors, suggesting that inborn or local genetic traits play key roles in increasing susceptibility to the development of abnormal veins. It is likely that genetic variation, persistent venous hypertension, and the consequences of chronic inflammation within the venous wall may be independent contributory elements.

\section{Materials and Methods: -}

The study was conducted over a period of one and a half years from January 2014 to September 2015. It included 100 patients having long saphenous varicosities with saphenofemoral incompetence who reported to surgical OPD SMHS hospital which is a tertiary care hospital in Kashmir valley attached to Government Medical College, Srinagar. It was a hospital based prospective study. The study protocol was in conformity with the ethical standards laid down in Declaration of Helsinki 2013 developed by World Medical Association (WMA). Informed consent was obtained from all 100 cases of long saphenous varicosities that were randomly selected and allocated into two groups. Each group comprised of 50 patients. Each patient was subjected to Doppler ultrasound to look for saphenofemoral incompetence and patency of deep veins. Any patient with deep venous thrombosis was excluded from study. Those patients designated for treatment of long saphenous varicosities by Trendelenburg's surgery (flush ligation of saphenofemoral junction without stripping) were subjected to it in minor operation theatre under local Anesthesia and were discharged the same day. Patient designated for treatment by stripping of long saphenous vein were planned for surgery which was later performed under general/spinal Anesthesia in General operation theatre. Each patient was evaluated prior to treatment as per the proforma.

Clinical history: A detailed history with reference to pain, aching sensations, swelling and heaviness of legs. Besides other symptom like itching, burning, fatigue, restless legs and venous ulceration were noted. Any history of varicose veins in family, history of any treatment for varicose veins in the past was noted.

General physical examination: Thorough general physical examination including appearance and built of patient, presence of anemia, cyanosis, jaundice or lymphadenopathy was noted. Pulse and blood pressure was recorded, thorough examination of chest, cardiovascular system and abdomen was carried out.

Local examination: Each patient was subjected to trendelenburgs test, cough impulse that and perthes test, to assess saphenofemoral junction, perforator veins and deep veins. The 100 cases taken up for study were confirmed as having long saphenous varicosities with saphenofemoral incompetence but with patent deep veins.

Investigation: Following preliminary investigation were carried out on all patients Complete Blood count, Blood sugar level, Liver Function Test, Urine examination, Chest X-ray and Echocardiography (ECG)

\section{Specific investigation:}

All patients were subjected to Doppler ultrasound. Doppler ultrasound was done to assess saphenofemoral junction and to exclude the possibilities of deep venous thrombosis that could be the cause of varicose veins.

\section{Procedure: -}

Flush ligation of saphenofemoral junction without stripping (Trendelenburgs Surgery): -

Preoperatively varicose veins were marked along with saphenofemoral junction and surgery was done under local anesthesia. A 5 to $6 \mathrm{~cm}$ incision was given $3 \mathrm{~cm}$ below and lateral to pubic tubercle parallel to inguinal ligament and saphenofemoral junction identified. All the tributaries of saphenous vein were ligated flush with femoral vein and divided. Wound was closed with silk suture and ASD applied. Elastic compression bandage was applied and the patient was discharged the same day.

Flush ligation of saphenofemoral function with stripping: -

The equipment used for stripping was Myer's stripper. Patients were admitted one day prior to surgery, their investigation completed and they were subjected to pre-anesthetic checkup. After clearance from anesthesia, varicose vein of the patients was marked. In the morning, patients were shifted to general operation theatre where stripping of long saphenous varicose vein was performed; either under general anesthesia or spinal anesthesia, flush ligation of saphenofemoral junction was done the same way as shown above. A small incision was made just below the knee around the long saphenous vein through which the stripper was past and taken out trough above opening and vein stripped from below downwards. This was immediately followed by compression bandaging to prevent 
hematoma formation. Post operatively the patients were shifted to ward with legs kept elevated. Patients were made ambulatory on the first postoperative day and the dressing was removed on the $2^{\text {nd }}$ post operative day; patients were usually discharged on the $2^{\text {nd }}$ or $3^{\text {rd }}$ post operative day.

\section{Follow-up:-}

All patients were advised to report in causality in case of any complication in the form of pain in legs, hematoma, wound infection or swelling of limbs.

Final Assessment Was Made at 6 months following the completion of procedure:-

$>$ Patients were assessed in terms of pain, paresthesia and immediate post-operative hematoma and wound infection.

$>$ Patient assessment: Patients were asked whether in their opinion the operation had been

- $\quad$ Successful (grade O).

- Partially successful (grade 1)

- Had made no difference to the lower limb (grade 2)

- Had made the veins of the leg worse (grade 3)

$>\quad$ Observer assessment: A clinical examination of the operated limb was undertaken and varicose vein recurrence graded from 0 to 3 .

- Grade 0 (No visible varicosities.)

- Grade 1 ( Minor reticular veins only)

- Grade 2 ( below knee varicosities)

- Grade 3 (above and below knee varicosities).

\section{Results:-}

The hundred patients were allocated into two groups of 50 patients each who either went flush ligation of saphenofemoral junction with stripping of long saphenous varicose vein or Trendelenburg's surgery (flush ligation of saphenofemoral junction) \& were called by $\mathbf{S}$ group \& $\mathbf{T}$ group respectively. The following observations were made:

\section{Sex distribution:-}

In all 30 patients were males $\& 70$ were females, the ratio of males $\&$ females was $3: 7$. in $\mathbf{S}$ group 13 patients were males \& 37 females with a male : female ratio of 1: 2.8. In $\mathbf{T}$ group 17 patients were males \& 33 females with a male female ratio of $1: 1.9$.

Age Distribution:- The age of patients ranged from 16 to 70 in both $\mathbf{S} \& \mathbf{T}$ group with a mean age of 44 years.

Table 1:- showing symptom distribution in all cases.

\begin{tabular}{|c|c|c|c|}
\hline S.no & Symptom & No. of cases & \%age \\
\hline 1 & Pain & 48 & $48 \%$ \\
\hline 2 & Heaviness & 75 & $75 \%$ \\
\hline 3 & Fatigue & 75 & $75 \%$ \\
\hline 4 & Restless legs & 58 & $58 \%$ \\
\hline 5 & Swelling & 38 & $38 \%$ \\
\hline 6 & Itching & 10 & $10 \%$ \\
\hline 7 & Cramps & 35 & $35 \%$ \\
\hline 8 & Ulceration & 2 & $2 \%$ \\
\hline
\end{tabular}

Family History: Family history was present in 70 patients who included 30 patients in T group and 40 patients in $\mathrm{S}$ group.

Local examination:- Each patient was subjected to:
1. Trendelenburgs test.
2. Perthes test
3. Cough Impulse test

\section{Trendelenburgs Test:-}

All patients in study were subjected to trendelenburgs test and in $100 \%$ of cases showed saphenofemoral incompetence which was considered as positive test. 


\section{Cough impulse test:-}

90\% of patients had positive cough impulse test (showing saphenofemoral incompetence) and $10 \%$ had negative cough impulse test. In $\mathbf{S}$ group $96 \%$ had positive cough impulse test and $4 \%$ had negative cough impulse test. In $\mathbf{T}$ group $84 \%$ had positive test and $16 \%$ had negative test.

\section{Perthes Test:-}

$60 \%$ of patients had positive perthes test and $40 \%$ had negative perthes test. In $\mathbf{S}$ group $68 \%$ had positive perthes test and 32\% had negative perthes test. In $\mathbf{T}$ group 52\% had positive test and $48 \%$ had negative test.

\section{Doppler ultrasound:-}

It showed sapheno-femoral incompetence in all the patients and in no patient whether in $\mathbf{S}$ or $\mathbf{T}$ group showed deep venous thrombosis.

Patients at 6 months following completion of treatment were assessed in terms of pain, Paresthesia and immediate post-operative hematoma and wound infection.

Table 2:- showing percentage of patients who developed pain, paresthesia and wound infection in T- group

\begin{tabular}{|c|c|c|}
\hline Clinical assessment & Number of patient & Percentage \\
\hline Pain & 4 & $8 \%$ \\
\hline Paresthesia & 3 & $6 \%$ \\
\hline Wound hematoma and infection & 2 & $4 \%$ \\
\hline
\end{tabular}

Table 3:- showing percentage of patients who developed pain, paresthesia and wound infection in S- group

\begin{tabular}{|c|c|c|}
\hline Clinical assessment & Number of patient & Percentage \\
\hline Pain & 3 & $6 \%$ \\
\hline Parathesia & 2 & $4 \%$ \\
\hline Wound hematoma and infection & 2 & $4 \%$ \\
\hline
\end{tabular}

Patient Assessment:- Six months following either treatment patients were asked whether, in their opinion, the operation had been:

$>$ Successful (grade 0)

$>$ Partially successful (grade 1)

$>$ Had made no difference to the lower limb (grade 2)

$>$ Had made the veins of the leg worse (grade3).

$64 \%$ of patients described the treatment with saphenofemoral junction ligation with stripping as successful (grade 0), as compared to $34 \%$ of patients describing it successful (grade 0) after saphenofemoral junction without stripping.

Table 4:- showing patient assessment of treatment following saphenofemoral junction ligation without stripping (Tgroup)

\begin{tabular}{|c|c|c|}
\hline Clinical assessment & Number of patient & Percentage \\
\hline Successful result & 17 & $34 \%$ \\
\hline Partially successful & 12 & $24 \%$ \\
\hline No difference & 11 & $22 \%$ \\
\hline Significantly worse & 10 & $20 \%$ \\
\hline
\end{tabular}

Table 5:- showing patient assessment of treatment following saphenofemoral junction ligation with stripping (Sgroup)

\begin{tabular}{|c|c|c|}
\hline Clinical assessment & Number of patient & Percentage \\
\hline Successful result & 32 & $64 \%$ \\
\hline Partially successful & 12 & $24 \%$ \\
\hline No difference & 4 & $8 \%$ \\
\hline Significantly worse & 2 & $4 \%$ \\
\hline
\end{tabular}


Observer assessment: Six months following either treatment, clinical examination of the operated limb was undertaken and varicose vein recurrence graded from 0 to 3:

Grade- 0 (no visible varicosities)

Grade -1 (minor reticular veins only)

Grade- 2 (below knee varicosities)

Grade -3 (above and below knee varicosities).

$62 \%$ of patients had no recurrent varicosities (grade 0) following saphenofemoral junction ligation with stripping as compared to $16 \%$ of patients having no recurrent varicosities (grade 0 ) following saphenofemoral junction ligation without stripping.

Table 6:- showing clinical recurrence following saphenofemoral junction ligation without stripping (T- group)

\begin{tabular}{|c|c|c|c|}
\hline Sno. & Clinical recurrence & No. of patients & \% age \\
\hline 1 & Grade 0 & 8 & $16 \%$ \\
\hline 2 & Grade 1 & 17 & $34 \%$ \\
\hline 3 & Grade 2 & 12 & $24 \%$ \\
\hline 4 & Grade 3 & 13 & $26 \%$ \\
\hline
\end{tabular}

Table 7:- showing clinical recurrence following saphenofemoral junction ligation with stripping (S- group).

\begin{tabular}{|c|c|c|c|}
\hline Sno. & Clinical recurrence & No. of patients & \%age \\
\hline 1 & Grade 0 & 31 & $62 \%$ \\
\hline 2 & Grade 1 & 10 & $20 \%$ \\
\hline 3 & Grade 2 & 5 & $10 \%$ \\
\hline 4 & Grade 3 & 4 & $8 \%$ \\
\hline
\end{tabular}

\section{Discussion:-}

Open surgical treatment of varicose veins with ligation and stripping of the great saphenous vein or short saphenous vein, combined with excision of large varicose veins, has been the standard of care of varicose vein treatment for more than a century. Invagination stripping was first attempted by Keller(3) in 1905,Charles Mayo in 1906(4) used an external stripper to remove the saphenous veins, and Babcock in 1907(5) introduced intraluminal stripping from the ankle to the groin. High ligation and ankle-to-groin stripping using a metal or, later, a disposable Codman or Myers stripper has become the technique of choice to remove the saphenous vein. Recognition of frequent saphenous nerve injury during ankle-to-groin stripping and a better understanding of the venous hemodynamics changed the technique to a limited, groin-to-knee stripping (6).It is important to note, however, that the technique of open surgery has also changed substantially in recent years, and today a much less invasive procedure is performed to treat the incompetent saphenous veins than at anytime before. Results of open surgery have continued to improve during the past decades, and high ligation/stripping of the great saphenous vein performed as an outpatient procedure is a safe and effective operation. Surgical treatment is superior to conservative management of varicose veins with use of elastic garments. In the REACTIV trial(7) results of surgery with compression treatment were compared with results of compression treatment alone in 246 patients with uncomplicated varicose veins (8). Surgical treatment included flush ligation of sites of reflux, stripping of the GSV, and multiple phlebectomies. At 2 years, surgery provided more symptomatic relief, better cosmetic results, and much-improved quality of life over conservative management.

\section{Conclusion:-}

Saphenofemoral ligation with or without stripping is equally effective in long saphenonous varicosities. However saphenofemoral ligation with stripping which aims to remove the varicose vein produces lasting results and results in better overall outcome. Saphenofemoral junction ligation with stripping of long saphenous varicosities is associated with greater morbidity due to bleeding and wound infection, which may result in prolonged hospital stay. More importantly there is increased incidence of injury to the saphenous nerve when the LSV is stripped from ankle to groin. But the incidence of injury to saphenous nerve may be reduced if LSV is stripped from upper calf to groin. Saphenofemoral junction ligation without stripping does not involve general anaesthesia and is an outpatient procedure. It allows preservation of patent great saphenous vein, which can be used as an arterial conduit at a lateral date. However it fails to normalize the venous function. We support the view that long saphenous varicosities are best treated by stripping in spite of the fact that the period of disability following surgery is significantly longer that after Saphenofemoral Junction Ligation only. 
Compliance with Ethical Standards: The study was in conformity with the ethical standards laid down in Declaration of Helsinki 2013 developed by World Medical Association(WMA).

Funding: This study was not funded by any agency.

Conflict of Interest:- All the authors declare that they have no potential conflict of interest.

\section{Refrences:-}

1. Raffetto JD, Khalil RA. Mechanisms of varicose vein formation: valve dysfunction and wall dilation. Phlebology 2008; 23:85-98.

2. Bergan JJ, Schmid-Schonbein GW, Smith PD, et al. Chronic venous disease. N Engl J Med 2006; 355:488-498.

3. Keller WL. A new method of extirpating the internal saphenous and similar veins in varicose conditions: a preliminary report. N Y Med J 1905;82:385.

4. Mayo CH. Treatment of varicose veins. Surg Obstet Gynecol 1906;2: 385-8.

5. Babcock WW. A new operation for the extirpation of varicose veins of the leg. N Y Med J 1907;86:153-6.

6. Holme JB, Skajaa K, Holme K. Incidence of lesions of the saphenous nerve after partial or complete stripping of the long saphenous vein. Acta Chir Scandin 1990;156:145-8.

7. Michaels JA, Campbell WB, Brazier JE, Macintyre JB, Palfreyman SJ, Ratcliffe J, et al. Randomised clinical trial, observational study and assessment of cost-effectiveness of the treatment of varicose veins (REACTIV trial). Health Technol Assess 2006;10:1-196.

8. Michaels JA, Brazier JE, Campbell WB, MacIntyre JB, Palfreyman SJ, Ratcliffe J. Randomized clinical trial comparing surgery with conservative treatment for uncomplicated varicose veins. Br J Surg 2006;93: 175-81. 